\title{
The effect of moderate alcohol drinking in nonalcoholic fatty liver disease
}

\author{
Jong Hwa Choi, Won Sohn, and Yong Kyun Cho \\ Division of Gastroenterology and Hepatology, Department of Internal Medicine, Kangbuk Samsung Hospital, Sungkyunkwan University \\ School of Medicine, Seoul, Korea
}

Nonalcoholic fatty liver disease (NAFLD) is defined by fat accumulation in liver that is not caused by excessive alcohol consumption. Safe limits of alcohol consumption in NAFLD are usually defined as alcohol consumption of less than 210 $\mathrm{g}$ per week for men and $140 \mathrm{~g}$ per week for women ( $30 \mathrm{~g} /$ day in men, $20 \mathrm{~g} /$ day in women) and alcohol consumption below safe limits is generally regarded as moderate alcohol consumption. Many studies have investigated the effects of moderate alcohol consumption on NAFLD patients. Some studies showed that moderate alcohol consumption prevented the progression of fibrosis in the liver, whereas other reports showed worsening of fibrosis in the liver based on serologic, radiologic and liver biopsy findings compared with effects on total abstainers. NAFLD is also thought to be a hepatic manifestation of metabolic syndrome, and when combined with excessive alcohol consumption results in the development of components of metabolic syndrome and systemic harmful effects. The effects of moderate alcohol consumption on NAFLD have yet to be established. (Clin Mol Hepatol 2020;26:662-669)

Keywords: Non-alcoholic fatty liver disease; Alcohol drinking; Liver cirrhosis

\section{INTRODUCTION}

Nonalcoholic fatty liver disease (NAFLD) is a chronic condition characterized by a series of events ranging from simple hepatic steatosis to nonalcoholic steatohepatitis (NASH), NASH-fibrosis and cirrhosis.' Histologically, it appears similar to alcohol-related liver disease, but distinguished by the amount of alcohol consumed, however, the amount of alcohol consumption accepted as "non-alcoholic" is disputed. ${ }^{2}$

There are various definitions for the moderate alcohol consumption. The lowest was $40 \mathrm{~g} /$ week and the highest was $308 \mathrm{~g} /$ week, according to the 11 papers that defined it. Except the lowest definition, the average of alcohol consumption is approximately 180 $\mathrm{g} /$ week, which is shown to satisfy the definition of NAFLD, 210 $\mathrm{g} /$ week for men and $140 \mathrm{~g} /$ week for women. ${ }^{3}$ The effects of moderate alcohol drinking on NAFLD progression and extrahepatic effects are not clear. Some studies showed that moderate alcohol consumption has beneficial effects in cardiovascular outcomes and prevention of NAFLD. ${ }^{4}$ However, recent studies suggest exacerbation of NASH and progression of hepatic fibrosis. ${ }^{5}$ Most studies had some limitations in that the outcomes were compared via non-invasive blood tests and imaging studies rather than changes

\begin{abstract}
Abbreviations:
ALT, alanine aminotransferase; BAC, blood alcohol concentration; $\mathrm{Cl}$, confidence interval; CVD, cardiovascular disease; HCC, hepatocellular carcinoma; HR, hazard ratio; KSHS, the Kangbuk Samsung Health Study; NAFLD, nonalcoholic fatty liver disease; NASH, nonalcoholic steatohepatitis; RR, relative risk; SCC, squamous cell carcinoma
\end{abstract}

\section{Corresponding author : Yong Kyun Cho}

Division of Gastroenterology and Hepatology, Department of Internal Medicine, Kangbuk Samsung Hospital, Sungkyunkwan University School of Medicine, 29 Saemunan-ro, Jongno-gu, Seoul 03181, Korea

Tel: +82-2-2001-2001, Fax: +82-2-2001-2610

E-mail: choyk2004.cho@samsung.com

https://orcid.org/0000-0002-9231-006X 
in liver histology, studies were almost cross-sectional design with selection bias, and the measurement of alcohol consumption through questionnaires may be insensitive, associated with recall bias.

In this review, we compared and summarized of the clinical results to date on the impact of moderate alcohol consumption on NAFLD patients.

\section{PROTECTIVE EFFECT}

The cross-sectional study in the obese group with body mass index higher than $35 \mathrm{~kg} / \mathrm{m}^{2}$ showed that moderate alcohol consumption prevented progression of steatohepatitis and lowered the prevalence of NAFLD. ${ }^{6}$ A number of subsequent studies have supported these findings. In a study investigating changes in 5-year serum alanine aminotransferase (ALT) levels, individuals with light (70-140 g/week) and moderate alcohol consumption (140-208 g/week) showed a lower rate of increase in serum ALT compared with consumption of $280 \mathrm{~g} /$ week or more. ${ }^{7}$ In addition, studies using abdominal ultrasound and computed tomography, light and moderate alcohol consumption lowered the likelihood of fatty liver development ${ }^{8-12}$ and was strongly associated with obesity but not with moderate alcohol consumption. ${ }^{9,10}$ A Japanese cohort study reported that the safe limit for alcohol consumption that prevented fatty liver development was less than $280 \mathrm{~g} /$ week in men..$^{13} \mathrm{~A}$ recent meta-analysis showed that modest drinking $(<70 \mathrm{~g} /$ week) has a protective effect against NAFLD/NASH development (Fig. 1). ${ }^{14}$ Liver biopsy-based cohort study in the National Institute of Health-NASH Clinical Research Network demonstrated moderate drinking was associated with low risk in NASH and NASH fibrosis development. ${ }^{15}$

Insulin resistance is one of the main factors causing liver steatosis and fibrosis. Insulin resistance increases the hepatic de novo lipogenesis and decreases the mechanism to inhibit adipose tissue lipolysis, resulting in the accumulation of fatty acids in the liver. Insulin resistance is also associated with secretion of adipokines and inflammatory cytokines, which causes adipose tissue dysfunction. The fat accumulated in the liver causes lipotoxicity, mitochondrial dysfunction with oxidative stress, production of reactive oxygen species, activation of endoplasmic reticulum stress, and ultimately, induction of hepatic fibrosis. ${ }^{16}$

Several studies have determined that moderate alcohol consumption reduces insulin resistance, yet the underlying mechanism still remains unknown. According to a study using the NAFLD animal model, a number of mRNA expressions were investigated; and among the many important factors in insulin signaling, the expression of glucose transporter 4 and serine phosphorylation of protein kinase, which acts as a mediator in the cell effects of insulin and is negatively controlled by tumor necrosis factor- $a$, was significantly higher in the NAFLD mice model exposed to moderate amounts of alcohol. ${ }^{17}$ Therefore, decreased in-

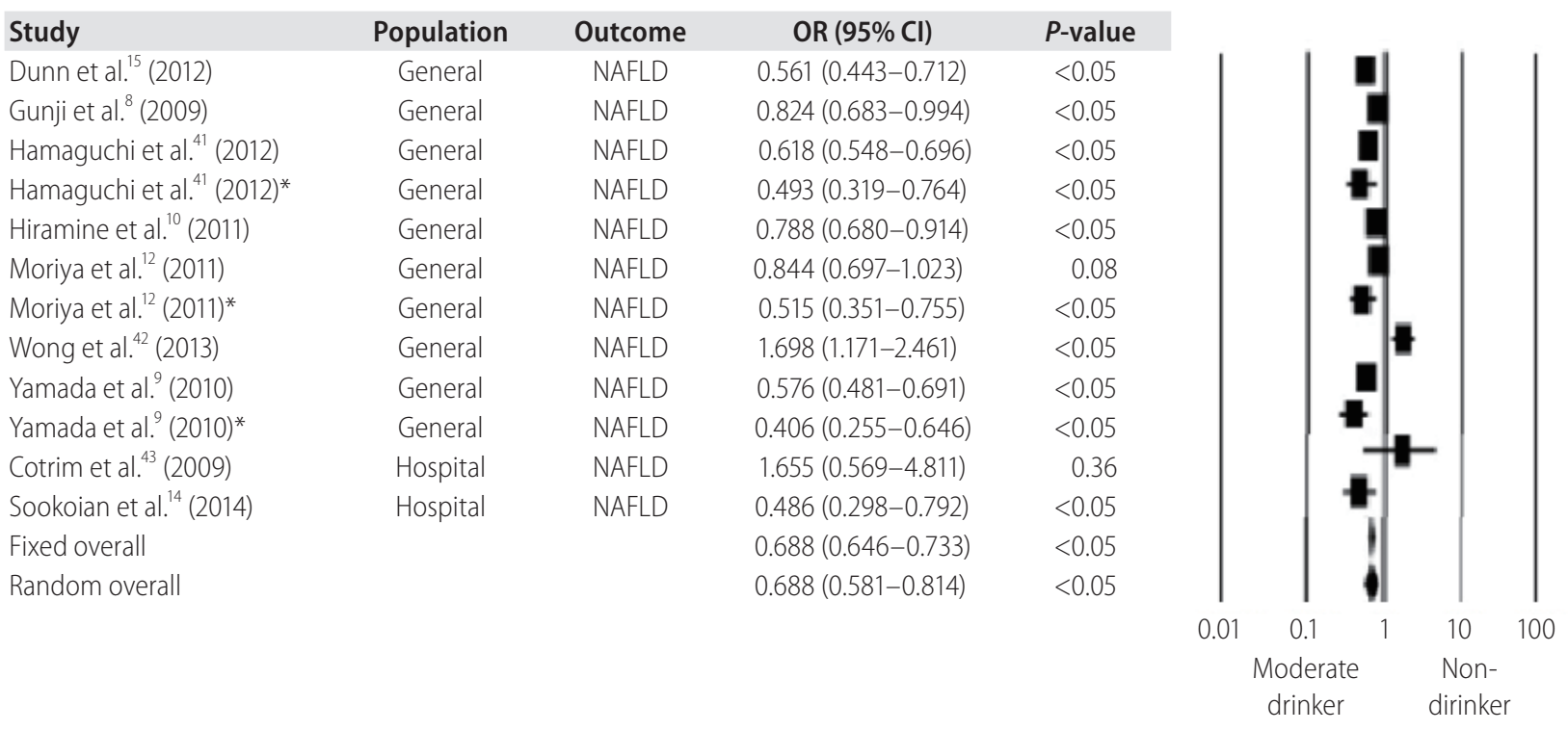

Figure 1. Moderate alcohol consumption decreases the risk of non-alcoholic fatty liver disease: a meta-analysis of 43,175 individuals. OR, odds ratio; $\mathrm{Cl}$, confidence interval; NAFLD, nonalcoholic fatty liver disease. *Female data. 
sulin resistance improved liver fibrosis. However, further research is needed in the future as mechanism has not been fully revealed.

The frequency and type of alcohol consumption had varying effects on fatty liver development. Especially binge drinking may be harmful drinking patterns and has been defined differently in many studies. According to the National Institute of Alcohol Abuse and Alcoholism, binge drinking was defined as the consumption of alcohol that makes a person reach a blood alcohol concentration (BAC) of $0.08 \mathrm{~g} / \mathrm{dL}$. BAC of $0.08 \mathrm{~g} / \mathrm{dL}$ generally occurs in men after consuming five or more drinks in about 2 hours, and in women after consuming four or more drinks over the same time span. ${ }^{18}$ Binge drinking resulted in increased liver fibrosis compared to non-binge drinkers. ${ }^{19}$ In the case of wine, it had the effect of preventing fatty liver development compared to other types of beer or liquor and the effect was attributed to non-alcoholic component in wine based on animal experiments, but the effect in humans needs to be elucidated. ${ }^{20}$ These results suggested that alcohol consumption below moderate levels contributed to the improvement of liver histology based on various mechanisms.

In addition, moderate alcohol drinkers might belong to higher socio-economic classes, with higher levels of education, more prone to physical activity, are used to consume alcohol within safe limits. In summary, a few studies showed that moderate drinking had beneficial effects on the development and progression of fatty liver, but studies were limited for the retrospective design and relatively short follow-up periods.

The protective results presented above are summarized in Table 1.

\section{DETRIMENTAL EFFECT}

It is also known that even modest alcohol consumption leads to the development and progression of fatty liver, and less than 20 $\mathrm{g} /$ day alcohol drinking in both men and women exacerbates the disease and increases liver-related mortality due to hepatocellular carcinoma. Even episodic drinking (at least 1 case/month) increases progression of fibrosis with increased alcohol consumption, as shown in patients with biopsy-proven NAFLD. ${ }^{21-23}$ Hepatocellular carcinoma (HCC) incidence increased synergistically in NAFLD patients compared to non-drinkers. ${ }^{24}$ In Korean participants, the incidence of HCC was associated with hepatits B or C viral infection, whereas in elderly NAFLD patients, a daily consumption of alcohol of $20 \mathrm{~g}$ increased the risk of HCC. Relatively safe alcohol consumption was 6 (standand) drinks/week or less, and as the consumption increased, the risk of cirrhosis increased in a dosedependent manner. ${ }^{25}$ In another Italian study, alcohol consumption less than $30 \mathrm{~g} /$ day was considered as the safe upper limit to

Table 1. Protective effect of moderate alcohol intake in NAFLD

\begin{tabular}{|c|c|c|c|c|}
\hline Study & Type of study & Patient & $\begin{array}{l}\text { Outcome } \\
\text { measure }\end{array}$ & Result \\
\hline Dixon et al..$^{6}$ (2001) & $\begin{array}{l}\text { Cross-sectional } \\
\text { cohort study }\end{array}$ & 105 patients & Liver biopsy & $\begin{array}{l}\text { Moderate alcohol consumption was associated with a } \\
\text { decreased risk of NASH }(\mathrm{OR}, 0.35 ; 95 \% \mathrm{Cl}, 0.12-1.00) \text {. }\end{array}$ \\
\hline Suzuki et al. (2007) & $\begin{array}{l}\text { Cross-sectional } \\
\text { and prospective } \\
\text { community- } \\
\text { based study }\end{array}$ & 1,177 patients & Blood ALT & $\begin{array}{l}\text { Moderate alcohol consumption was associated with } \\
\text { decreased odds (AOR, } 0.5[0.3-0.9], P=0.032) \text { in the } \\
\text { older group }\end{array}$ \\
\hline Gunji et al. ${ }^{8}$ (2009) & $\begin{array}{l}\text { Cross-sectional, } \\
\text { community- } \\
\text { based study }\end{array}$ & 5,599 patients & Ultrasonography & $\begin{array}{l}\text { Alcohol intake reduced the risk of fatty liver (OR, 0.82; } \\
95 \% \mathrm{Cl}, 0.68-0.99 ; \text { and } \mathrm{OR}, 0.75 ; 95 \% \mathrm{Cl}, 0.61-0.93 \text { ) }\end{array}$ \\
\hline Mitchell et al..$^{20}$ (2018) & $\begin{array}{l}\text { Cross-sectional, } \\
\text { cohort study }\end{array}$ & 187 patients & Liver biopsy & $\begin{array}{l}\text { Modest alcohol consumption ( } 1-70 \mathrm{~g} \text { per week) was } \\
\text { associated with a decreased risk of advanced fibrosis } \\
(\mathrm{OR}, 0.33 ; 95 \% \mathrm{Cl}, 0.14-0.78 ; P=0.01) \text { compared to } \\
\text { lifetime abstainers }\end{array}$ \\
\hline Dunn et al. ${ }^{15}$ (2012) & $\begin{array}{l}\text { Cross-sectional } \\
\text { cohort study }\end{array}$ & $\begin{array}{l}251 \text { lifetime modest } \\
\text { drinkers; } 331 \\
\text { non-drinkers }\end{array}$ & Liver biopsy & $\begin{array}{l}\text { Modest drinkers had significantly lower odds for fibrosis } \\
\quad(\mathrm{OR}, 0.56 ; 95 \% \mathrm{Cl}, 0.41-0.77)\end{array}$ \\
\hline Moriya et al. ${ }^{13}(2015)$ & $\begin{array}{l}\text { Community-based } \\
\text { cohort study }\end{array}$ & $\begin{array}{l}\text { 3,773 men and } \\
1,524 \text { women }\end{array}$ & Ultrasonography & $\begin{array}{l}\text { Men: moderate drinking }(\mathrm{OR}, 0.79 ; 95 \% \mathrm{Cl}, 0.68-0.90) \\
\text { Women: moderate drinking }(\mathrm{OR}, 0.71 ; 95 \% \mathrm{Cl}, 0.52-0.96)\end{array}$ \\
\hline
\end{tabular}

NAFLD, nonalcoholic fatty liver disease; OR, odds ratio; $\mathrm{Cl}$, confidence interval; ALT, alanine aminotransferase; AOR, adjusted odds ratio. 
prevent liver damage. ${ }^{26,27}$

The safe limit of alcohol consumption in patients with NAFLD should be reduced especially for those with comorbid diseases such as type 2 diabetes mellitus, obesity, hepatitis B or C viral infection, metabolic syndrome and advanced liver disease, which can cause liver fibrosis and damage even with relatively small amounts of alcohol consumption. Obesity is a detrimental factor increasing the risk associated with alcohol consumption. As mentioned before, NAFLD is not only a hepatic disease but also a component of metabolic syndrome, and develops combined with other metabolic diseases. The mechanism is not fully understood, but alcohol consumption and body mass index were strongly associated with long-term mortality. ${ }^{28-30}$ The mechanism of association between non-heavy alcohol drinking and fibrosis is not fully understood. The results presented above are summarized in Table 2.

Our data from Kangbuk Samsung Cohort study demonstrated that serum fibrosis markers in NAFLD increased even with low and moderate alcohol consumption. ${ }^{31}$ We performed a retrospective cohort study of 58,927 Korean adults with NAFLD and low fibrosis scores, who were followed for worsening of fibrosis scores. This cohort study was performed using a subsample of the Kangbuk Samsung Health Study (KSHS), a large cohort study conducted at the Health Screening Clinics of the Total Healthcare Center of the Kangbuk Samsung Hospital. In Korea, employees are required to participate in annual or biennial health examinations by the Industrial Safety and Health Law. Over $80 \%$ of participants of the KSHS are employees and are expected to undergo repeated health examinations every 1 to 2 years, depending on their age and job title, resulting in relatively high follow-up rates. It also provides a strong opportunity to perform a longitudinal cohort study. During the median follow-up of 8.3 years, 5,630 subjects with a low fibrosis score progressed to intermediate or high fibrosis score. After adjustment for confounders, the multivariable-adjusted hazard ratios (HRs) with 95\% confidence interval (CI) for worsening of the fibrosis- 4 index, one of the noninvasive fibrosis scores, comparing light and moderate drinkers with non-drinkers, were 1.06 (0.98-1.16) and 1.29 (1.18-1.40), respectively. Similarly, using the NAFLD fibrosis score, another fibrosis score, the corresponding $\mathrm{HRs}(95 \% \mathrm{Cl})$ comparing light and moderate drinkers, with non-drinkers were 1.09 (1.02-1.16) and 1.31 (1.23-1.40), respectively (Table 3). When the changes in alcohol drinking and confounders were monitored over time, the association of moderate drinkers with worsening of liver fibrosis score remained significant. Our findings indicate that even low amounts of alcohol are associated with progressive liver disease in NAFLD. Given that alcohol is a known carcinogen at low doses and harmful to liver health, patients with NAFLD should be advised against regular consumption even in non-heavy amounts of alcohol.

Indeed, alcohol consumption has been shown to have multiple effects on the liver. Alcohol reaches the liver via the portal vein, induces triglyceride accumulation and hepatic oxidative stress, and also increases gut permeability. But the mechanism of association between non-heavy alcohol drinking and liver fibrosis is not fully understood. In the future, longitudinal studies are expected

Table 2. Detrimental effect of moderate alcohol intake in NAFLD

\begin{tabular}{|c|c|c|c|c|}
\hline Study & Type of study & Patient & Outcome measure & Result \\
\hline Åberg et al. ${ }^{5}$ (2018) & Cohort study & 6,732 patients & $\begin{array}{l}\text { Liver disease } \\
\text { progression, HCC, } \\
\text { liver-related death }\end{array}$ & $\begin{array}{l}\text { Alcohol use (HR, 1.002; 95\% Cl, 1.001-1.002) } \\
\text { Alcohol was significant even when average } \\
\text { alcohol consumption was within the } \\
\text { limits currently defining nonalcoholic } \\
\text { fatty liver disease. }\end{array}$ \\
\hline Bellentani et al. ${ }^{23}$ (2000) & $\begin{array}{l}\text { Cross-sectional } \\
\text { cohort study }\end{array}$ & 257 patients & Ultrasonography & $\begin{array}{l}\text { Risk for steatosis was higher by 2.8-fold } \\
\quad(95 \% \text { Cl } 1.4-7.1)\end{array}$ \\
\hline Hézode et al. ${ }^{21}$ (2003) & Cohort study & $\begin{array}{l}260 \text { patients with } \\
\text { chronic hepatitis C }\end{array}$ & Liver biopsy & $\begin{array}{l}\text { The proportion of patients with moderate } \\
\text { (F2) or marked (F3) fibrosis or cirrhosis } \\
\text { (F4) gradually increased from } 29.0 \% \text { in } \\
\text { abstinent patients to } 67.6 \% \text { for an intake } \\
\text { between } 31 \text { and } 50 \mathrm{~g} / \text { day }(P<0.001)\end{array}$ \\
\hline Becker et al. ${ }^{26}$ (1996) & Cohort study & 13,285 patients & $\begin{array}{l}\text { Death certificates and } \\
\text { the hospital discharge } \\
\text { register }\end{array}$ & $\begin{array}{l}\text { A dose-dependent increase in relative } \\
\text { risk of developing alcohol-induced liver } \\
\text { disease for both men and women, with } \\
\text { the steepest increase among women. }\end{array}$ \\
\hline
\end{tabular}

NAFLD, nonalcoholic fatty liver disease; HCC, hepatocellular carcinoma; HR, hazard ratio; $\mathrm{Cl}$, confidence interval. 
Volume_26 Number_4 October 2020

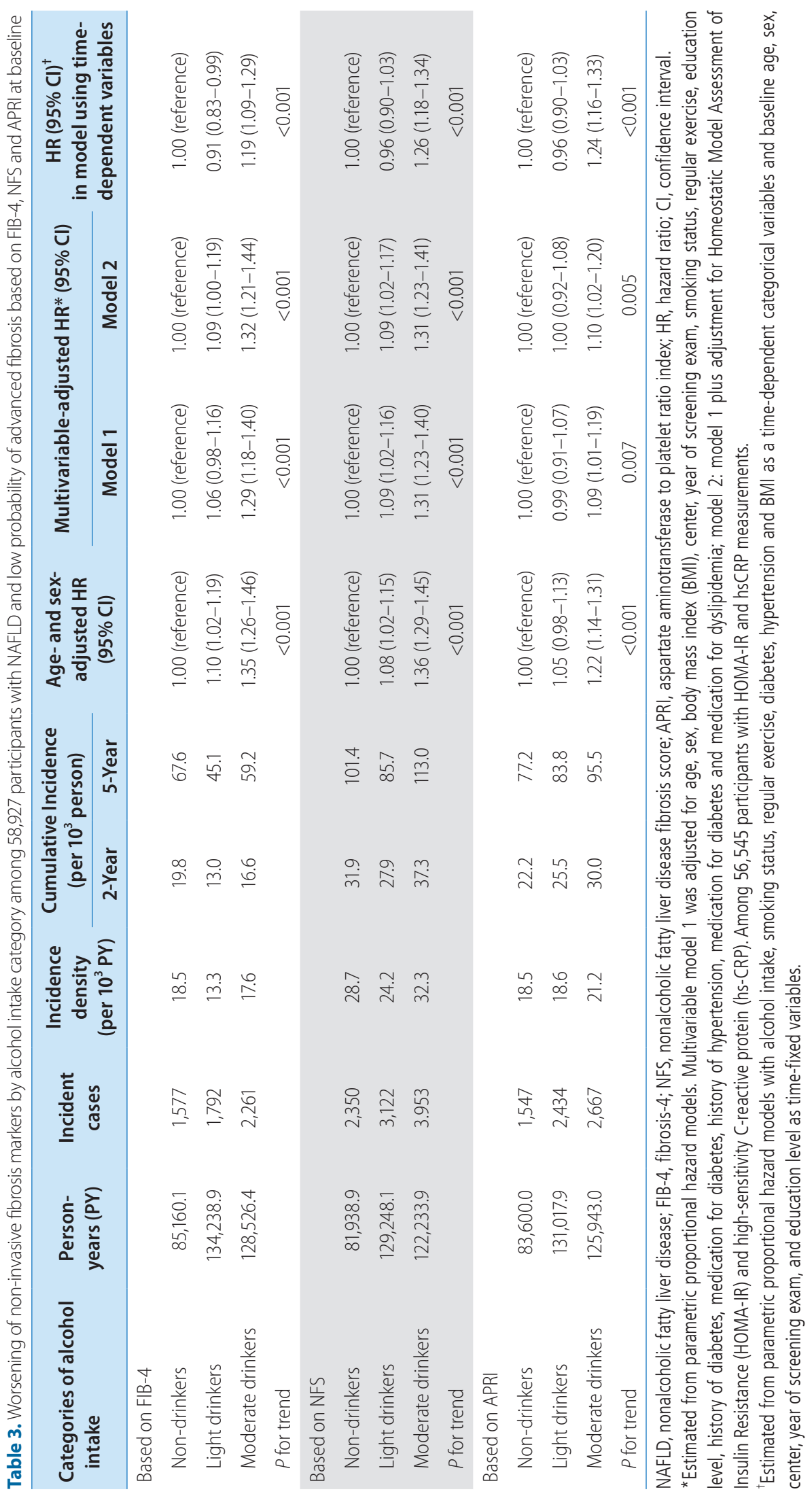


to demonstrate the inter-relationships between moderate alcohol consumption, genetic factors, impact of type/pattern of alcohol use and liver related outcomes.

\section{Extrahepatic effect of moderate alcohol consumption in NAFLD}

Among the various extrahepatic effects, the most common cause of death for NAFLD patients is cardiovascular disease (CVD). ${ }^{32}$ According to the case control study, NAFLD increases carotid artery intima-media thickness ${ }^{33}$ and artery wall stiffness. ${ }^{34}$ Twenty-seven studies, all of which were subsequently analyzed by larger meta-analysis, have also found that NAFLD and CVD shared a strong connection. ${ }^{35}$

As shown above, the risk of CVD is known to be high in NAFLD patients. However, there is not much evidence for the effect of moderate alcohol consumption on CVD risk. In cross-sectional and epidemiological studies, the effect of alcohol consumption on CVD risk in the general population showed a J-curve relationship. A cross-sectional study of 10,581 people in South Korea also showed that the prevalence of carotid plaques (55.3\% vs. 43.4\%, $P<0.001)$ and carotid artery stenosis $(11.0 \%$ vs. $5.5 \%, P<0.001)$ was higher in non-drinkers than in modest drinkers. ${ }^{36}$ Also, a Finnish study showed that alcohol consumption of up to $49 \mathrm{~g} /$ day was associated with a $22-40 \%$ reduction of incidental CVD. Compared to people who do not drink alcohol at all, people who drink 0-9 g/day had a $21 \%$ decrease in mortality. However, this effect was only found in non-smokers, and an increase in mortality was reported in those who consumed over $30 \mathrm{~g} /$ day of alcohol. ${ }^{37}$ However, it remains debatable whether moderate alcohol drinking in patients with NAFLD is effective in preventing in CVD, and it is difficult to reach a clear conclusion at this point.

Another cause of death in NAFLD patients is cancer. The relationship between alcohol consumption and cancer has been widely known since the past. In a meta-analysis study, moderate drinking significantly increased the incidence of male colorectal cancer and female breast cancer, whereas it decreased the incidence of both female and male hematologic malignancy. ${ }^{38}$ Another meta-analysis study showed that light drinking was associated with the risk of oropharyngeal cancer (relative risk [RR], 1.17; 95\% Cl, 1.06-1.29), esophageal squamous cell carcinoma (SCC) (RR, 1.30; 95\% Cl, 1.09-1.56), and female breast cancer (RR, 1.05; $95 \% \mathrm{Cl}, 1.02-1.08) .{ }^{39}$ Taken together, the two meta-analyses showed that the incidence of lung cancer, thyroid cancer, and hematological malignancy decreased, while the number of oropha- ryngeal cancer, esophageal SCC, as well as colorectal and female breast cancer increased.

\section{CONCLUSION}

Moderate alcohol consumption in patients with NAFLD has various effects. Some studies have reported that it prevents NAFLD development and progression, while others have reported deterioration of steatohepatitis and fibrosis. In addition, moderate alcohol consumption can be harmful in liver-related NAFLD outcomes in patients with NAFLD/NASH, especially for those with old age, obesity, metabolic syndrome, viral hepatitis, and advanced liver disease.

The extrahepatic beneficial effects associated with moderate alcohol drinking were reduction of insulin resistance and CVD risk, while the adverse effects included increase in the incidence of oropharyngeal cancer, esophageal SCC, as well as colorectal and female breast cancer.

Various results have been derived on the effect of moderate alcohol drinking on NAFLD, and there are many reasons for this. Some bias may exist, as the method for measuring the amount of alcohol consumption depends on the questionnaire. Moreover, the different definitions of moderate alcohol composition in each paper may also be the cause. ${ }^{40}$

Further longitudinal study is needed about the impact of moderate alcohol consumption on different stages of NAFLD. However, considering the basic medical principle of "Do No Harm", it is still premature to recommend moderate drinking in patients with NAFLD. With NASH and NASH-fibrosis concerns for an increase in mortality due to HCC, so it is questionable whether the current standard of moderate consumption is safe in patients with NAFLD especially for those with comorbid diseases or advanced liver fibrosis.

NAFLD is a multisystem disease that requires continuous attention and research. It is hoped that clear and comprehensive mechanisms will be established in the future, developing strategies to control the progression of the disease as well as its impact on moderate alcohol consumption.

\section{Authors' contribution}

JHC, WS, and YKC contributed to the design and writing of the manuscript. 


\section{Conflicts of Interest}

The authors have no conflicts to disclose.

\section{REFERENCES}

1. Metrakos $P$, Nilsson T. Non-alcoholic fatty liver disease--a chronic disease of the 21st century. J Biomed Res 2018;32:327-335.

2. Ntandja Wandji LC, Gnemmi V, Mathurin P, Louvet A. Combined alcoholic and non-alcoholic steatohepatitis. JHEP Rep 2020;2:100101.

3. Kwon I, Jun DW, Moon JH. Effects of moderate alcohol drinking in patients with nonalcoholic fatty liver disease. Gut Liver 2019;13;308-314.

4. Weng G, Dunn W. Effect of alcohol consumption on nonalcoholic fatty liver disease. Transl Gastroenterol Hepatol 2019;4:70.

5. Åberg F, Helenius-Hietala J, Puukka P, Färkkilä M, Jula A. Interaction between alcohol consumption and metabolic syndrome in predicting severe liver disease in the general population. Hepatology 2018;67:2141-2149.

6. Dixon JB, Bhathal PS, O'Brien PE. Nonalcoholic fatty liver disease: predictors of nonalcoholic steatohepatitis and liver fibrosis in the severely obese. Gastroenterology 2001;121:91-100.

7. Suzuki A, Angulo P, St Sauver J, Muto A, Okada T, Lindor K. Light to moderate alcohol consumption is associated with lower frequency of hypertransaminasemia. Am J Gastroenterol 2007;102:1912-1919.

8. Gunji T, Matsuhashi N, Sato H, Fujibayashi K, Okumura M, Sasabe N, et al. Light and moderate alcohol consumption significantly reduces the prevalence of fatty liver in the Japanese male population. Am J Gastroenterol 2009;104:2189-2195.

9. Yamada T, Fukatsu M, Suzuki S, Wada T, Yoshida T, Joh T. Fatty liver predicts impaired fasting glucose and type 2 diabetes mellitus in Japanese undergoing a health checkup. J Gastroenterol Hepatol 2010;25:352-356.

10. Hiramine $Y$, Imamura $Y$, Uto H, Koriyama C, Horiuchi M, Oketani M, et al. Alcohol drinking patterns and the risk of fatty liver in Japanese men. J Gastroenterol 2011;46:519-528.

11. Gunji T, Sato H, lijima K, Fujibayashi K, Okumura M, Sasabe N, et al. Modest alcohol consumption has an inverse association with liver fat content. Hepatogastroenterology 2012;59:2552-2556.

12. Moriya A, Iwasaki Y, Ohguchi S, Kayashima E, Mitsumune T, Taniguchi $\mathrm{H}$, et al. Alcohol consumption appears to protect against nonalcoholic fatty liver disease. Aliment Pharmacol Ther 2011;33:378388.

13. Moriya A, Iwasaki Y, Ohguchi S, Kayashima E, Mitsumune T, Taniguchi $\mathrm{H}$, et al. Roles of alcohol consumption in fatty liver: a longitudinal study. J Hepatol 2015;62:921-927.

14. Sookoian S, Castaño GO, Pirola CJ. Modest alcohol consumption de- creases the risk of non-alcoholic fatty liver disease: a meta-analysis of 43175 individuals. Gut 2014;63:530-532.

15. Dunn W, Sanyal AJ, Brunt EM, Unalp-Arida A, Donohue M, MCCullough AJ, et al. Modest alcohol consumption is associated with decreased prevalence of steatohepatitis in patients with nonalcoholic fatty liver disease (NAFLD). J Hepatol 2012;57:384-391.

16. Buzzetti E, Pinzani M, Tsochatzis EA. The multiple-hit pathogenesis of non-alcoholic fatty liver disease (NAFLD). Metabolism 2016;65:1038-1048.

17. Kanuri G, Landmann M, Priebs J, Spruss A, Löscher M, Ziegenhardt $D$, et al. Moderate alcohol consumption diminishes the development of non-alcoholic fatty liver disease (NAFLD) in ob/ob mice. Eur J Nutr 2016;55:1153-1164.

18. Courtney KE, Polich J. Binge drinking in young adults: data, definitions, and determinants. Psychol Bull 2009;135:142-156.

19. National Institute on Alcohol Abuse and Alcoholism (NIAAA). Drinking levels defined. NIAAA web site, <https://www.niaaa.nih.gov/ alcohol-health/overview-alcohol-consumption/moderate-bingedrinking >. Accessed 16 Aug 2020.

20. Mitchell T, Jeffrey GP, de Boer B, MacQuillan G, Garas G, Ching H, et al. Type and pattern of alcohol consumption is associated with liver fibrosis in patients with non-alcoholic fatty liver disease. Am J Gastroenterol 2018;113:1484-1493.

21. Hézode C, Lonjon I, Roudot-Thoraval F, Pawlotsky JM, Zafrani ES, Dhumeaux D. Impact of moderate alcohol consumption on histological activity and fibrosis in patients with chronic hepatitis C, and specific influence of steatosis: a prospective study. Aliment Pharmacol Ther 2003;17:1031-1037.

22. Ekstedt M, Franzén LE, Holmqvist M, Bendtsen P, Mathiesen UL, Bodemar $G$, et al. Alcohol consumption is associated with progression of hepatic fibrosis in non-alcoholic fatty liver disease. Scand J Gastroenterol 2009;44:366-374.

23. Bellentani S, Saccoccio G, Masutti F, Crocè LS, Brandi G, Sasso F, et al. Prevalence of and risk factors for hepatic steatosis in Northern Italy. Ann Intern Med 2000;132:112-117.

24. Ascha MS, Hanouneh IA, Lopez R, Tamimi TA, Feldstein AF, Zein NN. The incidence and risk factors of hepatocellular carcinoma in patients with nonalcoholic steatohepatitis. Hepatology 2010;51:19721978.

25. Yi SW, Choi JS, Yi JJ, Lee YH, Han KJ. Risk factors for hepatocellular carcinoma by age, sex, and liver disorder status: a prospective cohort study in Korea. Cancer 2018;124:2748-2757.

26. Becker U, Deis A, Sørensen TI, Grønbaek M, Borch-Johnsen K, Müller $C F$, et al. Prediction of risk of liver disease by alcohol intake, sex, and age: a prospective population study. Hepatology 1996;23:10251029.

27. Bellentani S, Saccoccio G, Costa G, Tiribelli C, Manenti F, Sodde M, et al. Drinking habits as cofactors of risk for alcohol induced liver 
Jong Hwa Choi, et al.

Moderate alcohol drinking in NAFLD

damage. The Dionysos Study Group. Gut 1997;41:845-850.

28. Bellentani S, Pozzato G, Saccoccio G, Crovatto M, Crocè LS, Mazzoran $L$, et al. Clinical course and risk factors of hepatitis $C$ virus related liver disease in the general population: report from the Dionysos study. Gut 1999;44:874-880.

29. Hart CL, Morrison DS, Batty GD, Mitchell RJ, Davey Smith G. Effect of body mass index and alcohol consumption on liver disease: analysis of data from two prospective cohort studies. BMJ 2010;340:c1240.

30. Armstrong GL, Wasley A, Simard EP, McQuillan GM, Kuhnert WL, Alter MJ. The prevalence of hepatitis C virus infection in the United States, 1999 through 2002. Ann Intern Med 2006;144:705-714.

31. Chang Y, Cho YK, Kim Y, Sung E, Ahn J, Jung HS, et al. Nonheavy drinking and worsening of noninvasive fibrosis markers in nonalcoholic fatty liver disease: a cohort study. Hepatology 2019;69:64-75.

32. Ekstedt $M$, Hagström $H$, Nasr $P$, Fredrikson $M$, Stål $P$, Kechagias $S$, et al. Fibrosis stage is the strongest predictor for disease-specific mortality in NAFLD after up to 33 years of follow-up. Hepatology 2015;61:1547-1554.

33. Targher G, Bertolini L, Padovani R, Zenari L, Zoppini G, Falezza G. Relation of nonalcoholic hepatic steatosis to early carotid atherosclerosis in healthy men: role of visceral fat accumulation. Diabetes Care 2004;27:2498-2500.

34. Lee YJ, Shim JY, Moon BS, Shin YH, Jung DH, Lee JH, et al. The relationship between arterial stiffness and nonalcoholic fatty liver disease. Dig Dis Sci 2012;57:196-203.

35. Oni ET, Agatston AS, Blaha MJ, Fialkow J, Cury R, Sposito A, et al. A systematic review: burden and severity of subclinical cardiovascular disease among those with nonalcoholic fatty liver; should we care?
Atherosclerosis 2013;230:258-267.

36. Sinn DH, Gwak GY, Cho J, Son HJ, Paik YH, Choi MS, et al. Modest alcohol consumption and carotid plaques or carotid artery stenosis in men with non-alcoholic fatty liver disease. Atherosclerosis 2014;234:270-275.

37. Åberg F, Puukka P, Salomaa V, Männistö S, Lundqvist A, Valsta L, et al. Risks of light and moderate alcohol use in fatty liver disease: follow-up of population cohorts. Hepatology 2020;71:835-848.

38. Choi YJ, Myung SK, Lee JH. Light alcohol drinking and risk of cancer: a meta-analysis of cohort studies. Cancer Res Treat 2018;50:474487.

39. Bagnardi V, Rota M, Botteri E, Tramacere I, Islami F, Fedirko V, et al. Light alcohol drinking and cancer: a meta-analysis. Ann Oncol 2013;24:301-308.

40. Kwon I, Jun DW, Moon JH. Effects of moderate alcohol drinking in patients with nonalcoholic fatty liver disease. Gut Liver 2019;13;308-314.

41. Hamaguchi M, Takeda N, Kojima T, Ohbora A, Kato T, Sarui H, et al. Identification of individuals with non-alcoholic fatty liver disease by the diagnostic criteria for the metabolic syndrome. World J Gastroenterol 2012;18:1508-1516.

42. Wong GL, Chan HL, Choi PC, Chan AW, Lo AO, Chim AM, et al. Association between anthropometric parameters and measurements of liver stiffness by transient elastography. Clin Gastroenterol Hepatol 2013;11:295-302.e1-e3.

43. Cotrim HP, Freitas LA, Alves E, Almeida A, May DS, Caldwell S. Effects of light-to-moderate alcohol consumption on steatosis and steatohepatitis in severely obese patients. Eur J Gastroenterol Hepatol 2009;21:969-972. 